\title{
PRESERVAÇÃO E CONSERVAÇÃO: REPRESENTAÇÕES SOCIAIS DE MEIO AMBIENTE DE PROFESSORES DE ESCOLAS URBANAS E DE ESCOLAS RURAIS NO SUDOESTE DO PARANÁ
}

\author{
PRESERVACIÓN Y CONSERVACIÓN: REPRESENTACIONES SOCIALES DE \\ MEDIO AMBIENTE EN MAESTROS DE ESCUELAS URBANAS Y DE \\ ESCUELAS RURALES EN EL SUROESTE DE PARANÁ
}

TEIXEIRA, Edival Sebastião edival@utfpr.edu.br Universidade Tecnológica Federal do Paraná MACHADO, Ederson Henrique de Souza edersonletrasutfpr@gmail.com Universidade Tecnológica Federal do Paraná

VARGAS, Luana Aparecida candyluh@hotmail.com Universidade Tecnológica Federal do Paraná

RESUMO O artigo apresenta resultados de uma pesquisa cujo objetivo foi identificar as representações sociais de meio ambiente de professores que atuam em diferentes instituições de ensino básico, localizadas em zonas urbanas e zonas rurais da região sudoeste do Paraná. Os dados foram coletados através de um instrumento de evocação livre, tendo como termo indutor a expressão "meio ambiente". Os dados indicam que o núcleo central da representação social de meio ambiente de ambos os grupos se estrutura e se estabiliza em torno da importância atribuída à preservação dos recursos naturais. Chama a atenção o fato de o elemento humano aparecer de modo periférico na representação de meio ambiente dos sujeitos, como se o homem não fosse o protagonista da questão ambiental.

PALAVRAS-CHAVE: Preservação. Conservação. Representações sociais. Meio ambiente. 
RESUMÉN EI artículo presenta investigación dirigida a identificar las representaciones sociales del medio ambiente de profesores que trabajan en distintas instituciones educativas ubicadas en zonas urbanas y rurales de la región suroeste de Paraná. Los datos fueron recolectados a través de un instrumento de evocación libre, con el término de inducción "medio ambiente". Los datos indican que el núcleo central de la representación social del medio ambiente de ambos grupos se estructura y se estabiliza en torno al énfasis en la preservación de los recursos naturales. Llama la atención sobre el hecho de que el elemento humano aparece de manera periférica en la representación del medio ambiente de los participantes, como si el hombre no fuera el protagonista de la cuestión ambiental.

PALABRAS-CLAVE: Preservación. Conservación. Representaciones sociales. Medio ambiente.

\section{INTRODUÇÃO}

Este artigo apresenta e discute resultados relativos à investigação acerca de possíveis relações entre as representações sociais de meio ambiente e práticas pedagógicas escolares em educação ambiental de professores que atuam em diferentes instituições de ensino básico, localizadas em zonas urbanas e zonas rurais da região sudoeste do Paraná.

A investigação partiu da hipótese de que haveria diferenças significativas entre as representações sociais de meio ambiente de professores de escolas urbanas e de professores de escolas rurais tendo em vista os respectivos contextos em que os docentes residem e trabalham.

No caso específico das escolas rurais, trata-se de instituições denominadas como Casas Familiares Rurais, as quais praticam o método da Pedagogia da Alternância. Na região sudoeste do Paraná, essas instituições estão localizadas em zonas rurais e atendem basicamente filhos de pequenos agricultores.

Parece não haver consenso na comunidade científica quanto ao conceito de meio ambiente. Assim, para Reigota (2007), nas pesquisas sobre representações sociais de meio ambiente, esse conceito tem sido representado mais comumente sob três concepções: antropocêntrica, globalizante e naturalista.

A concepção antropocêntrica focaliza a utilidade dos recursos naturais para a sobrevivência do ser humano. A concepção naturalista ressalta os aspectos naturais 
do ambiente em detrimento dos aspectos sociais. Por fim, a concepção globalizante observa as relações de reciprocidade entre a sociedade e a natureza.

Assim, os que se pautam pela primeira concepção tendem a ver o ambiente como reserva de recursos naturais para serem usados na medida das necessidades ditadas pela sobrevivência ou pelo mercado; os que se aglutinam na concepção globalizante consideram o humano como parte do ambiente, conceito este que englobaria aspectos naturais e culturais.

Nesta pesquisa foi utilizado o conceito apresentado por Marcos Reigota (2007, p. 154), para quem o meio ambiente refere-se a um "lugar determinado ou percebido, onde os elementos naturais e sociais estão em relações dinâmicas e em interação. Essas relações implicam processos de criação cultural e tecnológica e processos históricos e sociais de transformação do meio natural e construído".

Enquanto lugar determinado o conceito incorpora uma dimensão temporal e, por essa razão, ainda que se levem em conta os cuidados necessários para a generalização de resultados de investigação científica, é possível utilizar o recurso do recorte e mesmo assim se obter um conhecimento contextual aprofundado.

Enquanto lugar percebido, esse conceito leva em conta que cada sujeito 0 delimita a partir de suas representações, informações específicas, experiências e vivências cotidianas em seu tempo e espaço (REIGOTA, 2007).

$E$, enquanto concepção de espaço de interações dinâmicas, se aceita que as constantes transformações propiciadas pelas interações entre fatores bióticos e abióticos, entre grupos sociais e o meio natural ou construído, implicam transformações no próprio homem (REIGOTA, 2007).

Portanto, ao se tomar o conceito de meio ambiente enquanto espaço em que humanos e natureza tecem relações, pretende-se salientar que o estudo do meio ambiente e daquilo a ele relacionado - como a educação ambiental, por exemplo exigem ultrapassar limites disciplinares, principalmente do campo da biologia e considerar outros campos, como os das ciências sociais.

Conforme afirma Reigota (2007, p. 14), "o primeiro passo para a realização da educação ambiental deve ser a identificação das representações das pessoas envolvidas no processo educativo". E as representações sociais a que se refere o autor em questão são as de meio ambiente e de educação ambiental. 


\title{
2 AS REPRESENTAÇÕES SOCIAIS: ANCORAGEM E OBJETIVAÇÃO
}

\author{
Para Jodelet (2001, p. 22) uma representação social consiste em
}

\begin{abstract}
uma forma de conhecimento, socialmente elaborada e partilhada, com um objetivo prático, e que contribui para a construção de uma realidade comum a um conjunto social. Igualmente designada como saber do senso comum ou ainda saber ingênuo, natural, esta forma de conhecimento é diferenciada, entre outras, do conhecimento científico.
\end{abstract}

Dois processos cognitivos sustentam as representações sociais: a ancoragem e a objetivação. A ancoragem permite ao sujeito ajustar e comparar o desconhecido às categorias, idéias e imagens já contextualizadas relativamente a algo que lhe seja familiar.

A ancoragem consiste, pois, na incorporação de novos elementos de conhecimento numa rede de categorias familiares, a partir de três condições (MOSCOVICl, 2003): a primeira é a atribuição de um sentido ao objeto novo que se relacione com algum sentido já estabelecido, já portador de um significado; a segunda tem a ver com a instrumentalização do saber, mediante a qual o sujeito interpreta o conhecimento novo dando-lhe uma nova forma, traduzindo-o e incorporando-o ao seu universo socialmente vivido; e a terceira condição consiste no enraizamento, isto é, uma espécie de organização estrutural do objeto novo ao sistema de pensamento do sujeito.

Por sua vez, a objetivação é o processo pelo qual as idéias abstratas transformam-se em algo concreto, algo "quase tangível" nas palavras de Moscovici. É por esse processo que se dá a passagem de um ente imaginário a um ente quase material; "como, por exemplo, a passagem de um pensamento a um ato de comportamento manifesto" (TEIXEIRA; ALGERI, 2011, p.196).

Toda objetivação que se cristaliza passa a constituir o núcleo central de determinada representação (FRANCO, 2004a). Esse núcleo central é composto por um ou vários elementos cuja finalidade é, ao mesmo tempo, dar uma significação e uma espécie de organização à representação. Assim, é a presença de determinados 
elementos centrais que asseguram a permanência de uma representação (SÁ, 1996).

Por essa razão, a identificação desse núcleo permite inferir a existência de consensos relativamente compartilhados acerca de algum objeto, pois o núcleo central repercute a memória coletiva, o que implica admitir que sua formação seja marcada pelas condições contextuais do grupo social que o manifesta (SÁ, 1996; FRANCO, 2004a).

O núcleo central confere uma base relativamente estável à representação, de modo que se caracteriza por ser um tanto resistente à mudança. Por isso, "assegura a continuidade e a permanência de uma representação por tempos mais ou menos longos" (POLLI et al., 2009), a despeito do contexto imediato no qual a representação é posta em evidência. Contudo, de acordo com Sá (1996), em torno dos atributos centrais de uma representação orbitam um conjunto de elementos periféricos passíveis de captação e compreensão.

Esse sistema periférico é mais maleável e suscetível à mudança e, por essa razão, consegue "integrar as experiências e as histórias individuais às grupais, comportando, portanto, a heterogeneidade e as idiossincrasias" (TEIXEIRA; ALGERI, 2011, p. 196).

É por isso que, como afirmam Cromack, Bursztyn e Tura (2009, p. 628), o sistema periférico "promove a interface entre a realidade concreta e o núcleo central, atualizando-o e contextualizando-o constantemente, daí resultando sua mobilidade e flexibilidade, permitindo a expressão individualizada e tornando possível que a representação social se ancore na realidade do momento".

Então, levando-se em conta que as ações humanas são ancoradas em determinadas concepções de mundo e sociedade e que tais representações têm a capacidade de orientar condutas, pode-se admitir que as representações sociais de um grupo de professores sobre determinado tema orientam suas práticas pedagógicas a respeito do mesmo.

Em outras palavras, se as representações sociais enquanto fenômenos cognitivos são capazes de orientar práticas pedagógicas escolares no âmbito da educação ambiental, parece correto supor a importância e pertinência da utilização 
da teoria das representações sociais para se identificar o que professores pensam sobre meio ambiente.

\section{PROCEDIMENTOS METODOLÓGICOS}

A coleta de dados foi realizada através de um questionário composto por três partes: a primeira concentrava dados de identificação; a segunda, continha questões abertas centradas nas concepções dos docentes sobre desenvolvimento sustentável, educação e educação ambiental; a terceira consistia numa questão de evocação livre, tendo como termo indutor a expressão "meio ambiente".

Os dados obtidos através das questões abertas foram organizados e tratados através dos procedimentos usuais para análise de conteúdo, tais como descritos por Bardin (2002) e Franco (2004b).

A organização dos dados obtidos na evocação livre foi realizada com o auxílio da planilha eletrônica Microsoft Excel, conforme proposto por Teixeira e Algeri (2011) em seu estudo sobre representações sociais de meio ambiente e educação ambiental em docentes de casas familiares rurais.

Para a análise dos dados seguiram-se os procedimentos para identificação do núcleo central das representações sociais, conforme descritos por Sá (1996).

Os resultados obtidos mediante as diferentes técnicas empregadas foram confrontados, visando propiciar mais segurança quanto à identificação das representações sociais de meio ambiente dos sujeitos da pesquisa.

\section{RESULTADOS E DISCUSSÃO}

Os sujeitos da pesquisa foram 56 docentes que atuam em 13 escolas rurais, notadamente Casas Familiares Rurais, da região sudoeste do Paraná e 47 docentes de escolas urbanas localizadas nas cidades de Pato Branco, Itapejara do Oeste e Verê. As idades variavam entre 22 e 57 anos e a predominância feminina gira em torno de $65 \%$.

O núcleo central da representação de meio ambiente dos professores das escolas urbanas estabiliza-se em torno das seguintes categorias: Degradação, 
Natureza, Preservação e Água. Essas categorias, além de serem as mais salientes, serem as mais prontamente evocadas pelos sujeitos, também são consideradas como as mais importantes entre $58 \%$ e $100 \%$ das vezes em que seus elementos foram citados.

A categoria Degradação foi constituída pelos elementos lixo, poluição, efeito estufa, aquecimento global, agrotóxicos, industrialização, ar, água contaminada. Para a aglutinação dos elementos nessa categoria foi utilizado o recurso da aproximação semântica e, sobretudo, a análise dos sentidos dados pelos sujeitos quando das justificativas das escolhas feitas, bem como o confronto com a análise de conteúdo das demais questões dissertativas.

Assim, por exemplo, a evocação dos elementos industrialização e ar, que em termos de semântica estão distantes entre si e ambos distantes do vocábulo Degradação, foram incluídos nessa categoria porque ambos, quando apareceram, estavam ligados às evocações dos elementos aquecimento global e lixo.

Estes dois últimos elementos, que por sua vez claramente lembram degradação ambiental - embora não sejam semanticamente próximos - sempre apareceram juntos e/ou com outros elementos que também lembram degradação tais como água contaminada, agrotóxicos e aquecimento global, tanto nas evocações como nas respostas às questões dissertativas.

A categoria Natureza, por sua vez, comporta os elementos natureza, terra, homem, humano, fatores abióticos, fatores bióticos, solo, ecologia, planeta, animais, florestas e mata. Tal como na categoria anterior, nem todos esses elementos são necessariamente próximos entre si do ponto de vista semântico. Contudo, sempre que apareceram estiveram juntos e as justificativas dos sujeitos para suas escolhas sugerem o que afirmamos.

Nota-se aí a presença do elemento homem. Não obstante, geralmente o fator humano é citado pelos professores urbanos não como parte do ambiente, mas apenas como o elemento perturbador responsável pela degradação ambiental.

Os elementos preservação, conservação, reciclagem e reflorestamento foram agrupados na categoria Preservação. Quando os sujeitos são instados a justificar suas evocações ocorre um realce na importância da educação ambiental para a conservação dos recursos naturais, sobretudo da água. 
A categoria Água propriamente, isto é, seus elementos, todavia, não são tão salientes quanto os demais, ainda que na grande maioria das vezes em que aparecem são considerados como os mais importantes pelos sujeitos. Além disso, o elemento água geralmente aparece ligado a muitas outras categorias, sobretudo as que lembram a degradação ambiental.

Perifericamente na representação de meio ambiente dos docentes de escolas urbanas destacam-se categorias ligadas à conscientização para com a necessidade da preservação ambiental. A categoria Conscientização, por sinal, se constitui com elementos tais como educação, educação ambiental, consciência, conscientização. Mas, embora central à primeira vista, essa categoria é periférica porque seus elementos, embora estejam dentre os mais salientes, são considerados com pouca importância pelos sujeitos e nunca são os mais prontamente evocados.

Quanto aos docentes das escolas rurais, suas respostas indicam que em suas representações sociais de meio ambiente os elementos mais importantes são Água, Preservação, Conscientização e Sustentabilidade, nessa ordem. Esses sujeitos dão maior importância à água do que aos demais elementos do ambiente. Assim, essa categoria, juntamente com a categoria Preservação, é a mais saliente, mais prontamente evocada e considerada a mais importante em $80 \%$ das vezes em que é lembrada (TEIXEIRA; ALGERI, 2011).

As demais categorias centrais na representação de meio ambiente desses docentes sempre aparecem ligadas ao elemento água. Assim, a importância e saliência atribuídas à Preservação, via de regra, é justificada pela necessidade de preservar matas ciliares, preservar e proteger fontes, solos e demais recursos naturais, sobretudo os mais diretamente relacionados com a agricultura.

Além disso, a saliência da categoria Preservação e a sua ligação com a água têm a ver com o fato de que as Casas Familiares Rurais enfatizam pelo seu método a questão do desenvolvimento sustentável, além de manterem e incentivarem na região sudoeste do Paraná ações de proteção de nascentes.

Conscientização e Sustentabilidade são as demais categorias centrais na representação social em análise. Quando os sujeitos da pesquisa mencionam tais categorias, ligam-nas com a importância da sensibilização dos filhos dos pequenos 
agricultores para com a preservação ambiental e exploração sustentável dos recursos naturais cruciais para a atividade agrícola.

Como se disse acerca do grupo de professores de escolas urbanas, a questão da degradação ambiental Ihes parece crucial. O mesmo, todavia, não pode ser dito em relação aos docentes da zona rural. Com efeito, para esses últimos, a questão da degradação é secundarizada em favor da preservação dos recursos naturais, sobretudo da água.

Essa é uma das poucas diferenças encontradas entre os grupos, além do já mencionado fato de que nas respostas do grupo rural identificam-se mais facilmente suas ligações com características objetivas do contexto da agricultura.

\section{CONSIDERAÇÕES}

Os resultados da pesquisa não confirmaram a hipótese de que haveria diferenças significativas entre as representações sociais de meio ambiente de professores de escolas urbanas e de professores de escolas rurais, apesar do fato de que as representações sociais analisadas apresentarem características objetivas de cada contexto.

O núcleo central da representação social de meio ambiente de ambos os grupos se estrutura e se estabiliza em torno da importância atribuída à preservação dos recursos naturais, com destaque para a água, bem como em torno da degradação ambiental.

Tanto para os professores urbanos quanto para os professores das escolas rurais o meio ambiente é representado como um espaço natural degradado que precisa ser recuperado e preservado. Estranhamente, porém, justamente o principal agente da preservação ambiental, que o é homem, encontra-se quase ausente da representação social de meio ambiente desses professores.

Assim, chama a atenção o fato de o elemento humano aparecer de modo apenas periférico distante na representação social de meio ambiente desses educadores, como se o homem não fosse o protagonista da questão ambiental.

\section{EDIVAL SEBASTIÃO TEIXEIRA}


Doutor em Educação pela Universidade de São Paulo, Mestre em Educação pela Universidade Estadual Paulista Júlio de Mesquita Filho. Atualmente é Professor Associado da Universidade Tecnológica Federal do Paraná e Docente do Programa de Pós-Graduação em Desenvolvimento Regional. Líder do Grupo de Pesquisa Representações, Ambiente e Sociedade.

\section{EDERSON HENRIQUE DE SOUZA MACHADO}

Licenciado em Letras Português-Inglês pela Universidade Tecnológica Federal do Paraná, campus Pato Branco. Professor de Língua Inglesa em Pato Branco (PR).

\section{LUANA APARECIDA VARGAS}

Acadêmica do Curso de Licenciatura em Letras Português- Inglês, na Universidade Tecnológica Federal do Paraná, campus Pato Branco - PR. Bolsista PIBIC Iniciação Científica.

\section{REFERÊNCIAS}

BARDIN, Laurence. Análise de Conteúdo. Lisboa: Edições 70, 2002.

CROMACK, Luiza Maria Figueira; BURSZTYN, Ivani; TURA, Luiz Fernando Rangel. O olhar do adolescente sobre saúde: um estudo de representações sociais. Ciênc. saúde coletiva, vol.14 n. 2, Rio de Janeiro, mar./abr. 2009.

FRANCO, Maria Laura Barbosa Puglisi. Representações sociais, ideologia e desenvolvimento da consciência. Cadernos de Pesquisa, v. 34, n. 121, p. 169-186, jan./abr. 2004a.

FRANCO, Maria Laura Barbosa Puglisi. Análise de Conteúdo. Brasília: Líber Livros, 2004b.

JODELET, Denise. Representações Sociais: um domínio em expansão. Petrópolis: Vozes, 2001.

MOSCOVICI, Serge. Representações sociais: investigações em psicologia social. 4. ed. Petrópolis: Vozes, 2003.

POLLI, Gislei Mocelin et al. Representações sociais da água em Santa Catarina. Psicologia em Estudo, Maringá, v. 14, n. 3, p. 529-536, jul./set. 2009.

REIGOTA, Marcos. Meio ambiente e representação social. 7. ed. São Paulo: Cortez, 2007. 
SÁ, Celso Pereira. Núcleo central das representações sociais. Petrópolis: Vozes, 1996.

TEIXEIRA, Edival Sebastião; ALGERI, Fernanda Luiza. Representações de meio ambiente e educação ambiental: um estudo com docentes de Casas Familiares Rurais. Práxis Educativa, Ponta Grossa, v.6, n.2, p. 193-205, jul.-dez. 2011. Disponível em http://www.periodicos.uepg.br.

Agradecimento: Os autores agradecem ao Conselho Nacional de Desenvolvimento Científico e Tecnológico - CNPq, Brasil, pelo apoio financeiro concedido à pesquisa. 